\title{
Does chemotherapy or radiotherapy affect the postoperative complication in breast cancer patients who underwent immediate breast reconstruction with tissue expander?
}

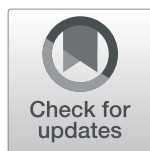

Sung Mi Jung ${ }^{1+}$, Byung-Joon Jeon ${ }^{2 \dagger}$, Jinsun Woo ${ }^{1}$, Jai Min Ryu' ${ }^{1}$, Se Kyung Lee ${ }^{1}$, Byung-Joo Chae ${ }^{1}$, Jonghan Yu', Seok Won Kim', Seok Jin Nam', Jai-Kyong Pyon², Goo-Hyun Mun², Sa Ik Bang ${ }^{2}$ and Jeong Eon Lee ${ }^{1 *}$

\begin{abstract}
Background: Immediate breast reconstruction with tissue expander in breast cancer patients who were expected to receive adjuvant therapy, such as chemotherapy or radiotherapy, has been a topic of debate. Postoperative complications from tissue expander procedures can delay the timing of adjuvant treatment and subsequently increase the probability of recurrence. The purpose of this study was to identify the impact of chemotherapy and radiotherapy on postoperative complications in patients who underwent immediate reconstruction (IR) using tissue expander.

Methods: We conducted a retrospective study of 1081 breast cancer patients who underwent mastectomy and IR using tissue expander insertion between 2012 and 2017 in Samsung Medical Center. The patients were divided into two groups based on complications (complication group vs. no complication group). Complication group was regarded to have surgical removal or conservative treatment based on clinical findings such as infection, capsular contracture, seroma, hematoma, rupture, malposition, tissue viability, or cosmetic problem. The complication group had 59 patients (5.5\%) and the no complication group had 1022 patients (94.5\%).

Results: In univariate analysis, adjuvant radiotherapy and adjuvant chemotherapy were significantly associated with postoperative complications. In multivariate analysis, however, only higher pathologic $N$ stage was significantly associated with postoperative complications $(p<0.001)$. Chemotherapy $(p=0.775)$ or radiotherapy $(p=0.825)$ were not risk factors for postoperative complications.

Conclusions: IR with tissue expander after mastectomy may be a treatment option even when the patients are expected to receive adjuvant chemotherapy or radiotherapy. These results will aid patients who are concerned about the complications of IR caused by chemotherapy or radiotherapy determine whether or not to have IR.

\footnotetext{
* Correspondence: jeongeon.lee@samsung.com

†'Sung Mi Jung and Byung-Joon Jeon contributed equally to this work.

'Division of Breast Surgery, Department of Surgery, Samsung Medical Center,

Sungkyunkwan University School of Medicine, Irwon-ro 81, Gangnam-gu,

06351 Seoul, South Korea

Full list of author information is available at the end of the article
}

\section{$\triangle B M C$}

(c) The Author(s). 2021 Open Access This article is licensed under a Creative Commons Attribution 4.0 International License, which permits use, sharing, adaptation, distribution and reproduction in any medium or format, as long as you give appropriate credit to the original author(s) and the source, provide a link to the Creative Commons licence, and indicate if changes were made. The images or other third party material in this article are included in the article's Creative Commons licence, unless indicated otherwise in a credit line to the material. If material is not included in the article's Creative Commons licence and your intended use is not permitted by statutory regulation or exceeds the permitted use, you will need to obtain permission directly from the copyright holder. To view a copy of this licence, visit http://creativecommons.org/licenses/by/4.0/ The Creative Commons Public Domain Dedication waiver (http://creativecommons.org/publicdomain/zero/1.0/) applies to the data made available in this article, unless otherwise stated in a credit line to the data. 
(Continued from previous page)

Trial registration: Patients were selected and registered retrospectively, and medical records were evaluated.

Keywords: Breast neoplasm, Chemotherapy, Adjuvant, Postoperative complications, Radiotherapy, Tissue expansion devices

\section{Background}

Breast cancer is the second most common cancer among women in the United States. In the United States, 250,520 new cases of female breast cancer were reported, and 42,000 women died of this cancer in 2017. For every 100,000 women, 125 new female breast cancer cases were reported and 20 women died of this cancer. The global burden of breast cancer in women, measured by incidence or mortality, is substantial and rising in several countries $[1,2]$.

Mastectomy with immediate reconstruction (IR) is one of the treatment option for breast cancer. Breast reconstruction after mastectomy has a positive impact on patients' psychosocial and sexual well-being. Moreover, immediate breast reconstruction can provide patients with the opportunity to reduce one additional surgery and costs instead of undergoing two separate procedures [3-7].

The performance of mastectomy followed by IR with a tissue expander in patients who were expected to receive adjuvant chemotherapy or radiotherapy has been debated. It is important to identify how adjuvant chemotherapy or radiotherapy affects surgical site complications in patients who have undergone IR. Postoperative complications related to tissue expander can miss the timing of adjuvant chemotherapy or radiotherapy and subsequently increase the probability of recurrence. Some previous studies reported that the incidence of postoperative complications caused by chemotherapy or radiotherapy in patients with tissue expander was higher than in patients without tissue expander $[8,9]$. Other studies have reported that immediate breast reconstruction may be a feasible surgical option in patients who were expected to receive adjuvant chemotherapy or radiotherapy and that it did not significantly affect the timing of adjuvant treatment or postoperative complications $[10,11]$.

The aim of this study was to determine the impact of chemotherapy and radiotherapy on postoperative complications in patients who received mastectomy and IR using tissue expander insertion.

\section{Methods \\ Patients}

This study was retrospectively performed on breast cancer patients who underwent mastectomy and IR

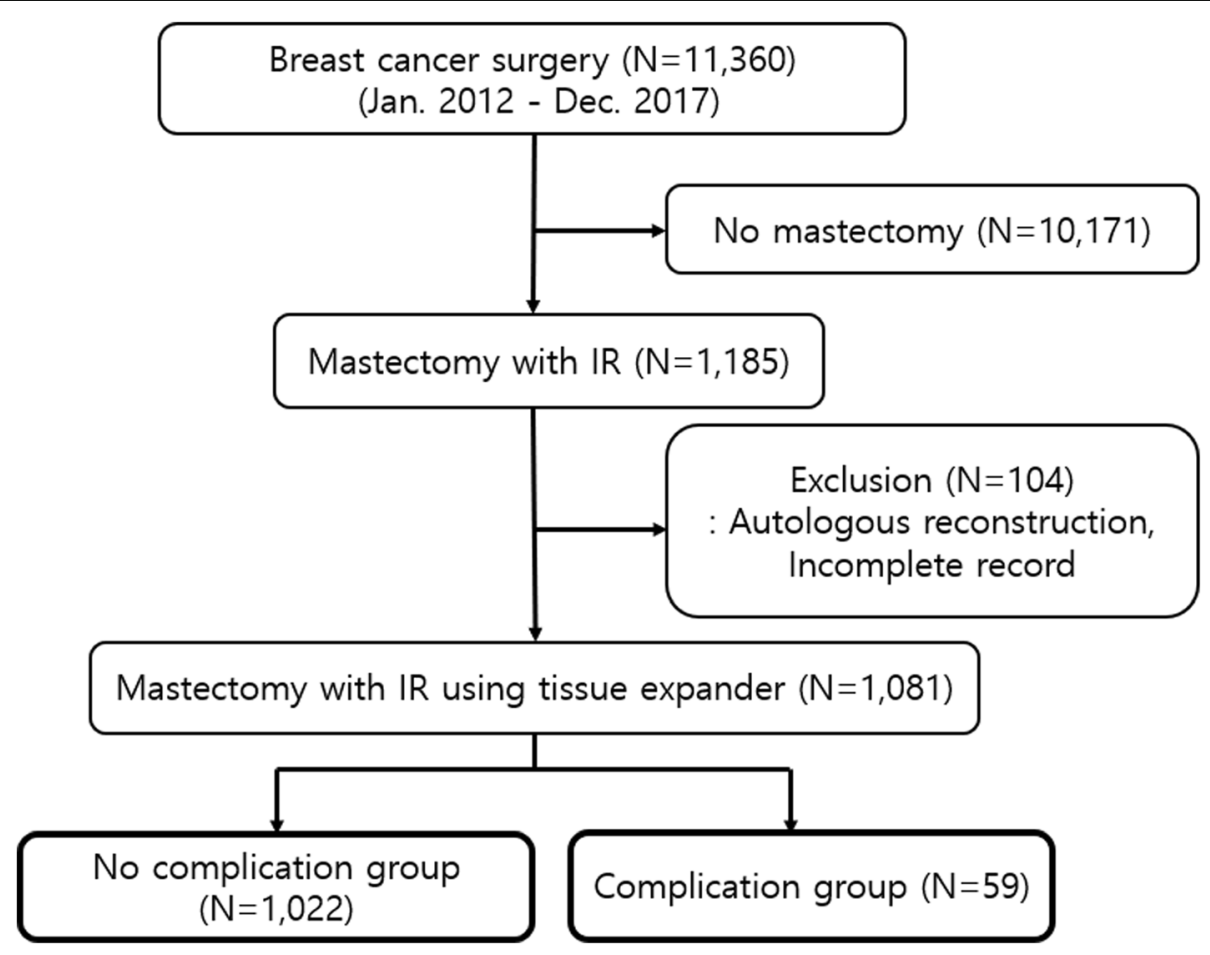

Fig. 1 Schematic flow of patients 
using tissue expander from January 2012 to December 2017 in Samsung Medical Center. The inclusion criteria included a total of 1081 female breast cancer patients who underwent nipple-sparing mastectomy or skin-sparing mastectomy with IR using tissue expander. The patients who received autologous reconstruction with deep inferior epigastric perforator free flap, latissimus dorsi flap or other tissues were excluded from this study (Fig. 1). There was no riskreducing mastectomy case in the inclusion criteria. The pathologic breast cancer staging followed the $\mathrm{Na}$ tional Comprehensive Cancer Network guidelines version 5.2020 and adjuvant therapy, such as chemotherapy or radiotherapy, was determined by stage and subtype [12].

Inclusion criteria were periodically monitored through physical examination, imaging and laboratory tests that were conducted at intervals of 6 months and 1 year, depending on the stage. The median follow-up was 448 days (range 27-2423 days). The patients were divided based on postoperative complications (complication group vs. no complication group). Complication group was regarded not only to have surgical removal of the tissue expander or implant which inserted after removing the tissue expander, but also to receive conservative treatment without surgical removal. Clinicians decided whether to have surgical removal or conservative treatment based on clinical findings such as infection, capsular contracture, seroma, hematoma, rupture, malposition, tissue viability, or cosmetic problem according to the Clavien-Dindo classification (CDC); CDC show acceptance and reproducibility through presumed parameters of severity of morbidity by correlating the various grades of complications that do not require treatment, or require treatment such as medication or surgery, or lead to death [13]. Surgical site infection (SSI) was diagnosed if there were clinical symptoms such as erythema, discharge, abscess, febrile sense, swelling, or tenderness, with or without isolation of pathogenic bacteria by the judgement of the clinicians. Patients who had signs of infection received surgical removal or conservative treatment with antibiotics. Surgical intervention for SSI was performed if the signs of infection continued despite to empirical antibiotic treatment, or rapid treatment of SSI was required due to planned adjuvant chemotherapy or radiotherapy. Capsular contracture was regarded according to Baker classification system with grade III (moderately contracture with firmness) or grade IV (severe contracture with symptom). Seroma or hematoma was considered as complication if surgical intervention or aspiration was required. Rupture or recurrence was found in breast ultrasound or magnetic resonance imaging performed during followup with clinical findings.

The data, including demographic factors, pathologic findings, and perioperative treatment were collected from the electronic medical records after Institutional Review Board Approval in Samsung Medical Center (IRB file no. 2019-10-146). Signed informed consent from the patients was not required.

\section{Statistical analysis}

Statistical analyses were performed using SPSS Statistics versions 25 (IBM Corp., Armonk, NY, USA). The continuous variables were compared using the Student's $t$ test between the two groups and the results are described as the mean and standard deviation with the range. The Chi-squared test and Fisher's exact test were conducted to compare the categorical variables between the two groups and the categorical variables are reported as number and percentage. All significant risk factors for postoperative complications were analyzed in univariate and binary logistic regression for multivariate analysis. Confidence intervals (95\%) and odds ratios were calculated and statistical significance was defined as $p<0.05$ in all tests.

\section{Results \\ Characteristics of patients}

A total of 11,360 patients underwent surgery for breast cancer from January 2012 to December 2017 in Samsung Medical Center. Of these, 1185 patients who underwent mastectomy with IR and 1081 patients who underwent IR with tissue expander insertion were included. There were 1022 patients (94.5\%) without postoperative complications (no complication group) and 59 patients (5.5\%) with postoperative complications (complication group) (Fig. 1). The median follow-up was 448 days (range 27-2423 days).

The baseline characteristics of the patients between the two groups were well balanced. The mean age of the patients at the time of breast cancer surgery was 43.29 years in the no complication group and 42.29 years in the complication group. There was no significant difference in the number the patients less than 40 years old and those more than 40 years old between the two groups. The mean body mass index (BMI) was $21.96 \mathrm{~kg} /$ $\mathrm{m} 2$ in the no complication group and $22.40 \mathrm{~kg} / \mathrm{m} 2$ in the complication group. There was no significant difference in the number of underweight, normal, or overweight patients defined by World Health Organization criteria (Asia-Pacific region) between the two groups. The incidence of patients with a history of diabetes mellitus (DM) or smoking was not significantly different between the two groups. Prior smokers were defined as 
Table 1 Baseline characteristics of patients

\begin{tabular}{|c|c|c|c|c|}
\hline Variable & $\begin{array}{l}\text { Total, } \mathrm{N} \\
\text { Mean } \pm \text { SD }\end{array}$ & No complication group, $\mathrm{N}(\%)$ Mean \pm SD & Complication group, $\mathrm{N}(\%)$ Mean \pm SD & $p$ \\
\hline Number of Patients & 1081 & $1022(94.5)$ & $59(5.5)$ & \\
\hline Age (years) & $43.29 \pm 7.40$ & $43.29 \pm 7.35$ & $42.29 \pm 8.30$ & 0.998 \\
\hline Age group & & & & 0.985 \\
\hline$<40$ years & 331 & $313(94.6)$ & $18(5.4)$ & \\
\hline$\geq 40$ years & 750 & $709(94.5)$ & $41(5.5)$ & \\
\hline BMI $\left(\mathrm{kg} / \mathbf{m}^{2}\right)$ & $21.98 \pm 2.93$ & $21.96 \pm 2.91$ & $22.40 \pm 3.19$ & 0.266 \\
\hline BMl group & & & & 0.383 \\
\hline$<18.5$ & 75 & $73(97.3)$ & $2(2.7)$ & \\
\hline $18.5-22.9$ & 668 & $633(94.8)$ & $35(5.2)$ & \\
\hline$\geq 23$ & 338 & $316(93.5)$ & $22(6.5)$ & \\
\hline DM & & & & 0.595 \\
\hline Yes & 16 & 15 (93.8) & $1(6.3)$ & \\
\hline No & 1065 & 1007 (94.6) & $58(5.4)$ & \\
\hline Smoking & & & & 0.439 \\
\hline Never & 1048 & 991 (94.6) & $57(5.4)$ & \\
\hline Prior & 7 & $6(85.7)$ & $1(14.3)$ & \\
\hline Current & 26 & $25(96.2)$ & $1(3.8)$ & \\
\hline
\end{tabular}

$B M I$ Body mass index, DM Diabetes mellitus

those who quit smoking more than 6 months earlier (Table 1).

The pathologic characteristics of lymphovascular invasion (LVI), pathologic $\mathrm{N}$ stage, and pathologic prognostic stage were significantly associated with postoperative complications. LVI was detected more often in the complication group than in the no complication group $(p=0.001)$. The proportion of patients with higher than pathologic $\mathrm{T} 1$ stage cancer was 91.5\% in the complication group and $79.7 \%$ in the no complication group. The proportion of patients with higher than pathologic N1 stage cancer was $54.2 \%$ in the complication group and $24.9 \%$ in the no complication group. There was a significant difference in the proportion of patients who were diagnosed with pathologic prognostic stage III cancer $(p=0.017)$. Invasive cancer was diagnosed $77.8 \%$ patients, and there was no significantly difference in two groups. The patients with ER-positive or PR-positive were $77.9 \%$, and with HER2-negative were $61.4 \%$ in two groups. The histologic feature and subtype were not significantly different between the two groups (Table 2).

There were significant differences in type of axillary surgery and adjuvant treatments. Patients in the complication group significantly more received axillary lymph node dissection and adjuvant post-mastectomy radiotherapy (PMRT) than patients in no complication group $(p<0.001)$ (Table 3).

\section{Risk factors of postoperative complications}

Postoperative complications developed in 59 patients. Twenty-three $(39.0 \%)$ of the 59 patients developed infections, and empirical antibiotics are administered. Seventeen of the 23 patients were treated with surgical removal, and 14 of the 17 patients had SSI which isolated pathogenic bacteria. Six of the 23 patients were treated with antibiotics without the removal of tissue expanders, and 3 of the 6 patients had SSI which isolated pathogenic bacteria. One of 59 patients was diagnosed with brain metastasis and underwent removal of the tissue expander for brain magnetic resonance imaging scans. One of two patients with persistent seroma formation after adjuvant radiotherapy required the removal of the tissue expander. For cosmetic effects, one patient with rippling had re-operation to change her implant and one patient had scar revision (Table 4).

Eleven (18.6\%) out of 59 patients recovered after conservative treatment without removal of the tissue expander or implant, and $48(81.4 \%)$ other patients required operation for complications (Table 4). Fifteen (31.3\%) out of 48 patients had their tissue expanders removed and $33(68.8 \%)$ other patients had their implants removed, which were inserted after tissue expander removal. The median time from surgery to the initiation of the adjuvant treatment, chemotherapy or radiotherapy, was 30 days, and adjuvant treatment was delayed in six of 35 patients who required adjuvant chemotherapy 
Table 2 Clinicopathologic characteristics of patients

\begin{tabular}{|c|c|c|c|c|}
\hline Variable & Total, N & No complication group, $\mathbf{N}(\%)$ & Complication group, $\mathrm{N}(\%)$ & $p$ \\
\hline Number of Patients & 1081 & $1022(94.5)$ & $59(5.5)$ & \\
\hline Location & & & & 0.032 \\
\hline Right & 514 & $484(94.2)$ & $30(5.8)$ & \\
\hline Left & 499 & $478(95.8)$ & $21(4.2)$ & \\
\hline Bilateral & 68 & $60(88.2)$ & $8(11.8)$ & \\
\hline Histopathology & & & & 0.939 \\
\hline Invasive cancer & 841 & $794(94.4)$ & $47(5.6)$ & \\
\hline DCIS & 199 & $189(95.0)$ & $10(5.0)$ & \\
\hline Other & 41 & $39(95.1)$ & $2(4.9)$ & \\
\hline Nuclear grade & & & & 0.966 \\
\hline Low & 153 & $144(94.1)$ & $9(5.9)$ & \\
\hline Intermediate & 663 & $627(94.6)$ & $36(5.4)$ & \\
\hline High & 265 & $251(94.7)$ & $14(5.3)$ & \\
\hline LVI & & & & 0.001 \\
\hline Yes & 285 & $258(90.5)$ & $27(9.5)$ & \\
\hline No & 796 & $764(96.0)$ & $32(4.0)$ & \\
\hline Pathologic T & & & & 0.118 \\
\hline Tis \& $p C R$ & 212 & $207(97.6)$ & $5(2.4)$ & \\
\hline $\mathrm{T} 1$ & 514 & $484(94.2)$ & $30(5.8)$ & \\
\hline $\mathrm{T} 2$ & 299 & $280(93.6)$ & $19(6.4)$ & \\
\hline$\geq \mathrm{T} 3$ & 56 & $51(91.1)$ & $5(8.9)$ & \\
\hline Pathologic N & & & & $<0.001$ \\
\hline No & 795 & $768(96.6)$ & $27(3.4)$ & \\
\hline $\mathrm{N} 1$ & 227 & $208(91.6)$ & $19(8.4)$ & \\
\hline N2 & 42 & $33(78.6)$ & $9(21.4)$ & \\
\hline N3 & 17 & $13(76.5)$ & $4(23.5)$ & \\
\hline Pathologic prognostic stage & & & & 0.017 \\
\hline 0 \& NRT & 207 & $199(96.1)$ & $8(3.9)$ & \\
\hline । & 456 & $431(94.5)$ & $25(5.5)$ & \\
\hline$\|$ & 342 & $326(95.3)$ & $16(4.7)$ & \\
\hline III & 76 & $66(86.8)$ & $10(13.2)$ & \\
\hline ER & & & & 0.445 \\
\hline Positive & 895 & $844(94.3)$ & $51(5.7)$ & \\
\hline Negative & 186 & $178(95.7)$ & $8(4.3)$ & \\
\hline$P R$ & & & & 0.192 \\
\hline Positive & 842 & $792(94.1)$ & $50(5.9)$ & \\
\hline Negative & 239 & $230(96.2)$ & $9(3.8)$ & \\
\hline C-erbB-2 & & & & 0.586 \\
\hline Positive & 296 & $280(94.6)$ & $16(5.4)$ & \\
\hline Negative & 664 & $630(94.9)$ & $34(5.1)$ & \\
\hline Unknown & 121 & $112(92.6)$ & $9(7.4)$ & \\
\hline Subtype & & & & 0.880 \\
\hline $\mathrm{HR}(+)$ & 900 & $849(94.3)$ & $51(5.7)$ & \\
\hline HR(-) C-erbB-2(+) & 121 & $116(95.9)$ & $5(4.1)$ & \\
\hline HR(-) C-erbB-2(-) & 56 & $53(94.6)$ & $3(5.4)$ & \\
\hline Unknown & 4 & $4(100.0)$ & $0(0.0)$ & \\
\hline
\end{tabular}


Table 3 Characteristics of surgical and medical treatment

\begin{tabular}{|c|c|c|c|c|}
\hline Variable & Total, $\mathrm{N}$ & No complication group, $\mathrm{N}(\%)$ & Complication group, $\mathrm{N}(\%)$ & $p$ \\
\hline Number of Patients & 1081 & $1022(94.5)$ & $59(5.5)$ & \\
\hline Axillary operation & & & & $<0.001$ \\
\hline SLNB & 876 & $839(95.8)$ & $37(4.2)$ & \\
\hline ALND & 205 & $183(89.3)$ & $22(10.7)$ & \\
\hline PMRT & & & & $<0.001$ \\
\hline Yes & 193 & $172(89.1)$ & $21(10.9)$ & \\
\hline No & 888 & $850(95.7)$ & $38(4.3)$ & \\
\hline Chemotherapy & & & & 0.062 \\
\hline No & 599 & $575(96.0)$ & $24(4.0)$ & \\
\hline NAC & 61 & $57(93.4)$ & $4(6.6)$ & \\
\hline Adjuvant chemotherapy & 421 & 390 (92.6) & $31(7.4)$ & \\
\hline
\end{tabular}

SLNB Sentinel lymph node biopsy, ALND Axillary lymph node dissection, PMRT Post-mastectomy radiotherapy, NAC Neoadjuvant chemotherapy

or radiotherapy because postoperative complications developed. Five of six patients needed removal of their tissue expanders and one of six patients recovered after conservative treatment without removal of their tissue expander. Five of six patients delayed their adjuvant chemotherapy and one of six patients delayed adjuvant radiotherapy. The median time from mastectomy to complications was 620 days (range 27-2423 days).

In univariate analysis, the pathologic results showed that LVI was associated with a higher risk of postoperative complication than that in patients without LVI (HR $=2.499,95 \%$ CI: 1.469 to $4.250, p=0.001)$. The patients with higher pathologic $\mathrm{N}$ stages had more postoperative complications. The patients with pathologic N2 stage had 7.758 times (95\% CI: 3.379 to $17.808, p<$ 0.001 ) the risk of postoperative complications as the patients with pathologic N0 stage, and those with pathologic N3 stage had 8.752 times (95\% CI: 2.677 to 28.612, $p<0.001)$ the risk of the pathologic N0 stage patients. In complication group, the mean amount of metastatic and retrieved lymph nodes were 4.27 and 19.00 in patients with higher pathologic N1 stage, respectively. The patients with pathologic prognostic stage III had 3.769 times (95\% CI: 1.428 to $9.947, p=0.007$ ) the risk of postoperative complications as the patients with pathologic prognostic stage 0 or no residual tumor (NRT) after neoadjuvant chemotherapy. Although the patients with axillary lymph node dissection (ALND), PMRT or adjuvant chemotherapy were associated with a higher risk of complications in univariate analysis, however, ALND, PMRT, or adjuvant chemotherapy were not significantly different between the two groups in multivariate analysis. In multivariate analysis, only the pathologic $\mathrm{N}$ stage was associated with postoperative complications $(p<$ 0.001 ) (Table 5). The regimens of adjuvant chemotherapy were independently analyzed, as a result,

Table 4 Type of postoperative complication

\begin{tabular}{llll}
\hline Complication type & Total, N & Surgical removal, N & No removal, N \\
\hline & 59 & 48 & 11 \\
Recurrence or Metastasis & 4 & 4 & 0 \\
Infection & 23 & 17 & 6 \\
Capsular contracture & 10 & 10 & 0 \\
Rupture & 3 & 3 & 0 \\
Malposition & 6 & 5 & 1 \\
Arm motion limitation & 1 & 1 & 0 \\
Hematoma & 1 & 0 & 1 \\
Wound dehiscence & 3 & 2 & 1 \\
Wound necrosis & 4 & 3 & 1 \\
Skin erythema \& Seroma & 1 & 1 & 0 \\
Cosmetic surgery & 2 & 1 & 1 \\
Desmoid tumor & 1 & 1 & 0
\end{tabular}

${ }^{a}$ Cosmetic surgery: rippling, scar revision 
Table 5 Univariate and multivariate analysis of risk factors for postoperative complication

\begin{tabular}{|c|c|c|c|c|}
\hline & Univariate & & Multivariate & \\
\hline & HR $(95 \% \mathrm{Cl})$ & $p$ & HR $(95 \% \mathrm{Cl})$ & $p$ \\
\hline Location & & & & \\
\hline Right (Ref.) & & 0.039 & & 0.020 \\
\hline Left & $0.709(0.400-1.256)$ & 0.238 & $0.659(0.366-1.185)$ & 0.163 \\
\hline Bilateral & $2.151(0.943-4.907)$ & 0.069 & $2.331(0.989-5.490)$ & 0.053 \\
\hline Histopathology & & & & \\
\hline Invasive cancer (Ref.) & & 0.939 & & 0.921 \\
\hline DCIS & $0.894(0.444-1.801)$ & 0.754 & $1.188(0.508-2.780)$ & 0.691 \\
\hline Other & $0.866(0.203-3.698)$ & 0.846 & $1.079(0.241-4.842)$ & 0.921 \\
\hline LVI & & & & \\
\hline Yes & $2.499(1.469-4.250)$ & 0.001 & $1.709(0.946-3.085)$ & 0.076 \\
\hline No (Ref.) & & & & \\
\hline Pathologic N & & & & \\
\hline NO (Ref.) & & $<0.001$ & & $<0.001$ \\
\hline N1 & $2.598(1.417-4.766)$ & 0.002 & $2.203(1.163-4.172)$ & 0.015 \\
\hline N2 & 7.758 (3.379-17.808) & $<0.001$ & $6.823(2.845-16.361)$ & $<0.001$ \\
\hline N3 & $8.752(2.677-28.612)$ & $<0.001$ & $6.331(1.831-21.886)$ & 0.004 \\
\hline Pathologic prognostic st & & & & \\
\hline 0 \& NRT (Ref.) & & 0.025 & & 0.179 \\
\hline । & $1.443(0.640-3.255)$ & 0.377 & $1.232(0.461-3.288)$ & 0.677 \\
\hline$\|$ & $1.221(0.513-2.905)$ & 0.652 & $0.054(0.170-1.713)$ & 0.295 \\
\hline III & 3.769 (1.428-9.947) & 0.007 & $0.564(0.145-2.200)$ & 0.410 \\
\hline Axillary op & & & & \\
\hline SLNB (Ref.) & & & & \\
\hline ALND & $3.144(1.826-5.414)$ & $<0.001$ & $1.450(0.674-3.123)$ & 0.342 \\
\hline PMRT + & & & & \\
\hline Yes & $2.731(1.564-4.769)$ & $<0.001$ & $1.101(0.468-2.589)$ & 0.825 \\
\hline No (Ref.) & & & & \\
\hline CTx. & & & & \\
\hline No (Ref.) & & 0.067 & & 0.775 \\
\hline NAC & $1.681(0.564-5.015)$ & 0.351 & $0.625(0.168-2.328)$ & 0.483 \\
\hline Adjuvant CTx. & $1.904(1.101-3.295)$ & 0.021 & $0.839(0.384-1.833)$ & 0.660 \\
\hline
\end{tabular}

DCIS Ductal carcinoma in situ, LVI Lymphovasvular invasion, NRT No residual tumor, SLNB Sentinel lymph node biopsy, ALND Axillary lymph node dissection, PMRT Post-mastectomy radiotherapy, NAC Neoadjuvant chemotherapy

doxorubicin, cyclophosphamide, and docetaxel regimen (AC-D) had 3.304 times (95\% CI: 1.483 to $7.361, p=$ 0.003 ) the risk of postoperative complications (Table 6).

\section{Discussion}

In our study, only the pathologic $\mathrm{N}$ stage was significantly associated with higher risk of postoperative complications in patients who received mastectomy and IR using tissue expander. Chemotherapy and radiotherapy did not significantly affect postoperative complications. Of the 1081 patients, 483 patients received adjuvant chemotherapy or radiotherapy and only six out of 483 patients delayed their adjuvant treatment because of postoperative complications.

Breast cancer patients have been able to select immediate breast reconstruction more easily without worrying cost because insurance has covered breast reconstruction for breast cancer patients since April 2015 in Korea. Several studies have demonstrated oncologic safety in the patients who underwent IR following mastectomy [14-16]. In addition, the majority of previous studies on the impact of chemotherapy or radiotherapy on postoperative complications after immediate breast reconstruction reported that chemotherapy or radiotherapy did not 
Table 6 Risk factors for postoperative complication by regimens of adjuvant chemotherapy

\begin{tabular}{llll}
\hline Regimen & $\mathbf{N}$ & Odds ratios $(\mathbf{9 5} \% \mathbf{C l})$ & $\boldsymbol{p}$ \\
\hline Patients & 421 & & \\
AC & 126 & $0.323(0.111-0.943)$ & 0.039 \\
AC-D & 187 & $3.304(1.483-7.361)$ & 0.003 \\
AC-P & 24 & $1.147(0.257-5.122)$ & 0.857 \\
FAC & 47 & $0.526(0.121-2.278)$ & 0.390 \\
TC & 22 & $0.583(0.076-4.482)$ & 0.604 \\
TCH & 13 & $0.000(0.000-0.000)$ & 0.999 \\
f/u loss & 2 & & \\
\hline
\end{tabular}

increase postoperative complications and immediate breast reconstruction did not affect the initiation of adjuvant treatment [5, 8-11, 17-24]. This study also reported that chemotherapy or radiotherapy did not affect postoperative complications in the patients who underwent immediate breast reconstruction with tissue expander.

Several studies reported that age, BMI, smoking, and DM were risk factors of postoperative complications in patients who underwent immediate breast reconstruction with tissue expanders or implants. Old age, increasing BMI, smoking, and DM can affect postoperative complications related to wound healing, leading to the removal of tissue expanders or implants [8, 25-27]. In this study, the mean age and BMI were 43.29 years and $21.98 \mathrm{~kg} / \mathrm{m} 2$, respectively, indicating that this study was performed mostly on young, normal-weight patients. Because our study had small numbers of patients with DM or current smokers, the analysis of the impact of DM or smoking on postoperative complications was not powerful enough to determine associations.

Our study showed that the postoperative complication rate was only $5.5 \%$ and the median time from mastectomy to complication was 620 days (range 27-2423 days). In addition, it is reported that only higher $\mathrm{N}$ stage was associated with postoperative complications. Lymphatic vessels play an important role in wound healing and wound healing is a complex process including inflammation, coagulation, and formation of granulation tissue with angiogenesis and lymphangiogenesis [28]. Metastatic axillary lymph nodes which have architectural distorsion, loss of hilum, or cortical thickness can affect scar formation and sensory nerves in surrounding tissues, therefore, the higher the $\mathrm{N}$ stage, the more the removal of this axillary lymph nodes affects the lymph drainage of the arm, which can result in postoperative complication such as breast edema and delayed wound healing [29]. In addition, previous studies have demonstrated that sentinel lymph node biopsy and ALND have association with postoperative complication such as lymphedema, wound infection, and seroma formation $[30,31]$. In our study, the most common cause of complications was infections, $2.1 \%$. Some studies have reported that the incidence of seroma formation was 3$85 \%$ after breast or axillary surgery and seroma aspiration was a risk factor for SSI [32-35], and in our study, only one of 1081 patients after IR had seroma formation in surgical site and underwent surgical removal of tissue expander. To improve the completion of breast reconstruction, surgeons try to prevent seroma formation at the surgical site by minimizing the dead space and educating patients on how to exercise the arm that is ipsilateral to the breast cancer $[34,36]$. Other studies have demonstrated that early drain removal is safe to prevent seroma formation, however, there was no investigation of the timing of drain removal in our study [37, 38].

Although the probability of chemotherapy or radiotherapy increases as the pathologic prognostic stage increases, chemotherapy or radiotherapy was not significantly related to postoperative complication in this study. It has been a controversy whether it is appropriate to do an IR or to do a delayed breast reconstruction in patients with advanced breast cancer. Chemotherapy may be associated toxicity, immunosuppression, and fat necrosis, which may lead to wound healing and PMRT may cause local damage such as fat necrosis, wound dehiscence, flap fibrosis $[39,40]$. Therefore, clinicians have not actively recommended IR in patients who were expected to have adjuvant chemotherapy or radiotherapy because it is possible to increase the probability of recurrence by missing the appropriate timing of adjuvant chemotherapy or radiotherapy. However, surgical technique about breast reconstruction with tissue expander has improved over the past years, resulting in more natural, reassuring, and better results. Therefore, breast reconstruction surgery has recently been an indispensable part of breast cancer surgery. In addition to the development of surgical technique, chemotherapy or radiotherapy did not significantly increase postoperative complication and delay timing of adjuvant treatment in our study. In this study, 35 out of 59 patients who had postoperative complications underwent adjuvant chemotherapy or radiotherapy, and only six of 35 patients delayed their adjuvant treatment because of postoperative complication. Five patients suffered from infections during adjuvant chemotherapy and one patient with a headache was diagnosed with brain metastasis during adjuvant radiotherapy. Another 29 of 35 patients who underwent adjuvant treatment developed postoperative complications after adjuvant treatment.

In this study, adjuvant AC-D regimens significantly impact postoperative complications. Specific chemotherapeutic agents may adversely impact wound healing on an immediate tissue expander or implant reconstruction. 
Changing the chemotherapeutic agents according to side effects may improve postoperative complication and outcomes $[8,41]$.

This study had some limitations. It was a retrospective review and thus, had selection bias. Also, there are other variables in immediate autologous breast reconstructions because this study was limited to IR with tissue expander. Further studies overcoming these limitations can help to determine the effects of IR.

\section{Conclusions}

Several previous studies have reported oncologic safety and no difference in complications after IR following mastectomy in patients with breast cancer [14-16]. However, many surgeons still hesitate to perform immediate breast reconstruction for patients with high-stage breast cancer. Our data suggested that chemotherapy or radiotherapy were not risk factors for postoperative complications, and did not cause delay adjuvant treatment. This study will help patients who are concerned about the complications of IR caused by chemotherapy or radiotherapy determine whether or not to have IR.

\section{Abbreviations}

ALND: Axillary lymph node dissection; BMI: Body mass index; CDC: ClavienDindo classification; DM: Diabetes mellitus; IR: Immediate reconstruction; LVI: Lymphovascular invasion; NRT: No residual tumor; PMRT: Postmastectomy radiotherapy; SSI: Surgical site infection

\section{Acknowledgements}

The authors are grateful to all participating patients.

\section{Authors' contributions}

SMJ, BJJ, and JEL contributed to the conception and design of the study. SMJ, JSW, JMR, SKL, BJC, JHY, SWK, SJN, JKP, GHM and SIB collected and analyzed the data. SMJ, BJJ and JEL wrote and reviewed the manuscript. All authors reviewed and approved the final version of the manuscript.

\section{Funding}

No funding was obtained for this study.

\section{Availability of data and materials}

The datasets used and/or analysed during the current study are available from the corresponding author on reasonable request.

\section{Ethics approval and consent to participate}

The data, including demographic factors, pathologic findings, and perioperative treatment were collected from the electronic medical records after Institutional Review Board Approval in Samsung Medical Center (IRB file no. 2019-10-146). Signed informed consent from the patients was not required.

\section{Consent for publication}

Not applicable.

\section{Competing interests}

The authors declare that they have no competing interests.

\section{Author details}

${ }^{1}$ Division of Breast Surgery, Department of Surgery, Samsung Medical Center, Sungkyunkwan University School of Medicine, Irwon-ro 81, Gangnam-gu, 06351 Seoul, South Korea. ${ }^{2}$ Department of Plastic Surgery, Samsung Medical Center, Sungkyunkwan University School of Medicine, Irwon-ro 81,

Gangnam-gu, 06351 Seoul, South Korea.
Received: 27 July 2020 Accepted: 13 December 2020

Published online: 22 January 2021

\section{References}

1. U.S. Cancer Statistics Working Group. U.S. Cancer Statistics Data Visualizations Tool, based on 2019 submission data (1999-2017): U.S. Department of Health and Human Services, Centers for Disease Control and Prevention and National Cancer Institute; www.cdc.gov/cancer/dataviz, released in June 2020

2. Coughlin SS. Epidemiology of breast cancer in women. In: Ahmad A, editor. Breast cancer metastasis and drug resistance: challenges and Progress. Edn. Cham: Springer International Publishing; 2019. p. 9-29.

3. Heimes AS, Stewen K, Hasenburg A. Psychosocial aspects of immediate versus delayed breast reconstruction. Breast Care (Basel). 2017;12(6):374-7.

4. Bykowski MR, Emelife PI, Emelife NN, Chen W, Panetta NJ, de la Cruz C. Nipple-areola complex reconstruction improves psychosocial and sexual well-being in women treated for breast cancer. J Plast Reconstr Aesthet Surg. 2017;70(2):209-14.

5. Baek SH, Bae SJ, Yoon Cl, Park SE, Cha CH, Ahn SG, et al. Immediate breast reconstruction does not have a clinically significant impact on adjuvant treatment delay and subsequent survival outcomes. J Breast Cancer. 2019; 22(1):109-19.

6. Cemal Y, Albornoz CR, Disa JJ, McCarthy CM, Mehrara BJ, Pusic AL, et al. A paradigm shift in U.S. breast reconstruction: part 2. The influence of changing mastectomy patterns on reconstructive rate and method. Plast Reconstr Surg. 2013:131(3):320e-6e.

7. Nguyen AT, Chang DW. Discussion: a paradigm shift in U.S. breast reconstruction: increasing implant rates. Plast Reconstr Surg. 2013;131(1): 24-5.

8. Dolen UC, Schmidt AC, Um GT, Sharma K, Naughton M, Zoberi I, et al. Impact of Neoadjuvant and adjuvant chemotherapy on immediate tissue expander breast reconstruction. Ann Surg Oncol. 2016;23(7):2357-66.

9. Mitchem J, Herrmann D, Margenthaler JA, Aft RL. Impact of neoadjuvant chemotherapy on rate of tissue expander/implant loss and progression to successful breast reconstruction following mastectomy. Am J Surg. 2008; 196(4):519-22.

10. Hamahata A, Kubo K, Takei H, Saitou T, Hayashi $Y$, Matsumoto H, et al. Impact of immediate breast reconstruction on postoperative adjuvant chemotherapy: a single center study. Breast Cancer. 2015;22(3):287-91.

11. Jethwa KR, Kahila MM, Whitaker TJ, Harmsen WS, Corbin KS, Park SS, et al. Immediate tissue expander or implant-based breast reconstruction does not compromise the oncologic delivery of post-mastectomy radiotherapy (PMRT). Breast Cancer Res Treat. 2017;164(1):237-44.

12. National Comprehensive Cancer Network. Breast cancer version 5; 2020. http:// www.nccn.org/professionals/physician_gls/PDF. Accessed July 15th, 2020.

13. Dindo D, Demartines N, Clavien P-A. Classification of surgical complications: a new proposal with evaluation in a cohort of 6336 patients and results of a survey. Ann Surg. 2004:240(2):205-13.

14. Ryu JM, Paik HJ, Park S, Yi HW, Nam SJ, Kim SW, et al. Oncologic outcomes after immediate breast reconstruction following Total mastectomy in patients with breast cancer: a matched case-control study. J Breast Cancer. 2017;20(1):74-81.

15. Ryu JM, Park S, Paik HJ, Nam SJ, Kim SW, Lee SK, et al. Oncologic safety of immediate breast reconstruction in breast cancer patients who underwent Neoadjuvant chemotherapy: short-term outcomes of a matched casecontrol study. Clin Breast Cancer. 2017;17(3):204-10.

16. Lee SB, Lee JW, Son BH, Eom JS, Kim EK, Lee TJ, et al. Oncologic safety of skin-sparing mastectomy followed by immediate reconstruction in young patients with breast cancer. Asian J Surg. 2019:42(1):274-82.

17. Furey PC, Macgillivray DC, Castiglione CL, Allen L. Wound complications in patients receiving adjuvant chemotherapy after mastectomy and immediate breast reconstruction for breast cancer. J Surg Oncol. 1994;55(3):194-7.

18. Decker MR, Greenblatt DY, Havlena J, Wilke LG, Greenberg CC, Neuman HB. Impact of neoadjuvant chemotherapy on wound complications after breast surgery. Surgery. 2012;152(3):382-8.

19. Song J, Zhang $X$, Liu Q, Peng J, Liang $X$, Shen $Y$, et al. Impact of neoadjuvant chemotherapy on immediate breast reconstruction: a metaanalysis. PLoS One. 2014;9(5):e98225.

20. Warren Peled A, Itakura K, Foster RD, Hamolsky D, Tanaka J, Ewing C, et al. Impact of chemotherapy on postoperative complications after mastectomy and immediate breast reconstruction. Arch Surg. 2010;145(9):880-5. 
21. Yoon AP, Qi J, Brown DL, Kim HM, Hamill JB, Erdmann-Sager J, et al. Outcomes of immediate versus delayed breast reconstruction: results of a multicenter prospective study. Breast (Edinburgh, Scotland). 2018;37:72-9.

22. Anker CJ, Hymas RV, Ahluwalia R, Kokeny KE, Avizonis V, Boucher KM, et al. The effect of radiation on complication rates and patient satisfaction in breast reconstruction using temporary tissue expanders and permanent implants. Breast J. 2015;21(3):233-40.

23. Lam TC, Borotkanics R, Hsieh F, Salinas J, Boyages J. Immediate two-stage prosthetic breast reconstruction failure: radiation is not the only culprit. Plast Reconstr Surg. 2018;141(6):1315-24.

24. Allué Cabañuz M, Arribas Del Amo MD, Gil Romea I, Val-Carreres Rivera MP, Sousa Domínguez R, Güemes Sánchez AT. Direct-to-implant breast reconstruction after neoadjuvant chemotherapy: a safe option? Cir Esp. 2019;97(10):575-81.

25. Garvey PB, Villa MT, Rozanski AT, Liu J, Robb GL, Beahm EK. The advantages of free abdominal-based flaps over implants for breast reconstruction in obese patients. Plast Reconstr Surg. 2012;130(5):991-1000.

26. Ilonzo N, Tsang A, Tsantes S, Estabrook A, Thu Ma AM. Breast reconstruction after mastectomy: a ten-year analysis of trends and immediate postoperative outcomes. Breast (Edinburgh, Scotland). 2017;32:7-12.

27. Sada A, Day CN, Hoskin TL, Degnim AC, Habermann EB, Hieken TJ, Mastectomy and immediate breast reconstruction in the elderly: trends and outcomes. Surgery. 2019;166(4):709-14.

28. Lee S-J, Park C, Lee JY, Kim S, Kwon PJ, Kim W, et al. Yoon Y-s: generation of pure lymphatic endothelial cells from human pluripotent stem cells and their therapeutic effects on wound repair. Sci Rep. 2015;5:11019.

29. Young-Afat DA, Gregorowitsch ML, van den Bongard DH, Burgmans I, van der Pol CC, Witkamp AJ, et al. Breast edema following breast-conserving surgery and radiotherapy: patient-reported prevalence, determinants, and effect on health-related quality of life. JNCI Cancer Spectr. 2019;3(2):pkz011.

30. Killelea BK, Long JB, Dang W, Mougalian SS, Evans SB, Gross CP, et al. Associations between sentinel lymph node biopsy and complications for patients with ductal carcinoma in situ. Ann Surg Oncol. 2018;25(6):1521-9.

31. Cuadrado GA, de Andrade MFC, Akamatsu FE, Jacomo AL. Lymph drainage of the upper limb and mammary region to the axilla: anatomical study in stillborns. Breast Cancer Res Treat. 2018;169(2):251-6.

32. Ota D, Fukuuchi A, Iwahira Y, Kato T, Takeuchi M, Okamoto J, et al. Identification of complications in mastectomy with immediate reconstruction using tissue expanders and permanent implants for breast cancer patients. Breast Cancer. 2016;23(3):400-6.

33. Moyer KE, Potochny JD. Technique for seroma drainage in implant-based breast reconstruction. J Plast Reconstr Aesthet Surg. 2012;65(12):1614-7.

34. ten Wolde B, van den Wildenberg FJ, Keemers-Gels ME, Polat F, Strobbe $L$. Quilting prevents seroma formation following breast cancer surgery: closing the dead space by quilting prevents seroma following axillary lymph node dissection and mastectomy. Ann Surg Oncol. 2014;21(3):802-7.

35. Boostrom SY, Throckmorton AD, Boughey JC, Holifield AC, Zakaria S, Hoskin $\mathrm{TL}$, et al. Incidence of clinically significant seroma after breast and axillary surgery. J Am Coll Surg. 2009;208(1):148-50.

36. Coveney EC, O'Dwyer PJ, Geraghty JG, O'Higgins NJ. Effect of closing dead space on seroma formation after mastectomy--a prospective randomized clinical trial. Eur J Surg Oncol. 1993;19(2):143-6.

37. Thomson DR, Trevatt AE, Furniss D. When should axillary drains be removed? A meta-analysis of time-limited versus volume controlled strategies for timing of drain removal following axillary lymphadenectomy. J Plast Reconstr Aesthet Surg. 2016;69(12):1614-20.

38. Unalp HR, Onal MA. Analysis of risk factors affecting the development of seromas following breast cancer surgeries: seromas following breast cancer surgeries. Breast J. 2007;13(6):588-92.

39. El-Sabawi B, Sosin M, Carey JN, Nahabedian MY, Patel KM. Breast reconstruction and adjuvant therapy: a systematic review of surgical outcomes. J Surg Oncol. 2015;112(5):458-64.

40. Sekiguchi K, Kawamori J, Yamauchi H. Breast reconstruction and postmastectomy radiotherapy: complications by type and timing and other problems in radiation oncology. Breast Cancer. 2017;24(4):511-20.

41. Oh E, Chim H, Soltanian HT. The effects of neoadjuvant and adjuvant chemotherapy on the surgical outcomes of breast reconstruction. J Plast Reconstr Aesthet Surg. 2012;65(10):e267-80.

\section{Publisher's Note}

Springer Nature remains neutral with regard to jurisdictional claims in published maps and institutional affiliations.
Ready to submit your research? Choose BMC and benefit from:

- fast, convenient online submission

- thorough peer review by experienced researchers in your field

- rapid publication on acceptance

- support for research data, including large and complex data types

- gold Open Access which fosters wider collaboration and increased citations

- maximum visibility for your research: over $100 \mathrm{M}$ website views per year

At BMC, research is always in progress.

Learn more biomedcentral.com/submissions 